\title{
Synthesis and Olfactory Characteristics of Hydroxyether Derivatives of Methyl Eugenol
}

\author{
*1OKOPI, SO; ${ }^{2}$ AFFIKU, LM \\ ${ }^{* 1}$ Depatment of Chemistry, Benue State University, Makurdi, Nigeria \\ ${ }^{2}$ Department of Chemistry, Collage of Education, Akwanga, Nigeria \\ *Corresponding author email: okopis@live.com
}

\begin{abstract}
Methyl eugenol is a naturally occurring substance found in the essential oils of several plant species. It is a cheap and abundant material with a rather limited interest as perfuming ingredient. This research investigated the structure-odour relationship of methyl eugenol and its derivatives, focusing on the chemical transformation of the double bond to hydroxyether derivatives in a controlled manner. Two derivatives 2-(4-ethyl-3-methoxybenzyl)oxirane (68.8\% yield) and 1-(3,4-dimethoxyphenyl)-3-ethoxypropan-2-ol (63.58\% yield), were synthesized from methyl eugenol. This research found that the odour characteristic of 2-(4-ethyl-3-methoxybenzyl)oxirane[floral, fresh, slight lime and sweet]compounds, is clearly different from the odours of the 1-(3,4-dimethoxyphenyl)-3-ethoxypropan-2-ol [Glue-like, pungent, and Caramel-like]. It is evident from our observations that double bond substitution and functional alteration of the methyl eugenol modifies the perceived odour of methyl eugenol derivative. Thus, structural modification overall led to an increase in odour potency.
\end{abstract}

DOI: https://dx.doi.org/10.4314/jasem.v24i9.3

Copyright: Copyright $(\subset) 2020$ Okopi and Affiku. This is an open access article distributed under the Creative Commons Attribution License (CCL), which permits unrestricted use, distribution, and reproduction in any medium, provided the original work is properly cited.

Dates: Received: 22 August 2020; Revised: 09 September 2020; Accepted: 20 September 2020

Keywords: Fragrance, Methly-Eugenol, Ether, Olfactory characteristic, Epoxidation.

The chemistry behind smell is complex and fascinating. Until the end of the nineteenth century, perfumers worked with a relatively small number of materials, which were naturally derived, and they created a correspondingly small range of fragrance types and expensive end-product, primarily in the citrus and floral families. (Antoniotti, 2014; Harman, 2002). The explosive growth of organic chemistry at the end of that century made innumerable new materials available to the perfumer, necessitating a rational method of fragrance creation (Harman, 2002). A great deal has been achieved in both the understanding of the biology of smell (olfaction) as well as the development of new and unique fragrances (Sell, 2006) via chemical modifications. The connections between chemical constitution on the one hand, and odour on the other, have been continually studied for many years (Serra et al., 2005; Ohloff et al., 1994; Ohloff, 1992; Buck and Axel, 1991), but the precise mechanism underlying this effect is not understood. In another word, we still lack an understanding of why chemicals smell the way they do. For instance, substances with very similar molecular structures (stereoisomers) may give rise to odours that are quite different from each other, as in the case of (-)-Carvone and (+)-Carvone (Noma and Asakawa 2010; Brookes et al., 2009; Engen, 1982). On the other hand, molecules with different structures can produce very similar odours. Example, vanillin, p- nitroguaiacol, and p-cyanoguaiacol all have similar odours, but varying in strength.

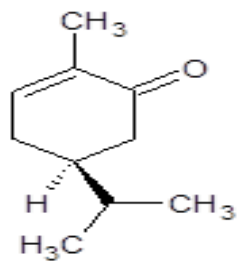

(S)- (-) Carvone

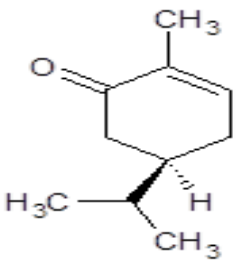

(R)-(+) Carvone<smiles>COc1cc(C=O)ccc1O</smiles>

Fig 1: Structures of (S)-(-), (R)-(+) Carvone, Vanillin, pnitroguaiacol, and p-cyanoguaiacol

However, the studies of odour and the structure of the odour-causing molecules have revealed some correlation. The olfactory quality of a fragrant material is correlated to the presence and concentration of impact odorant molecules and it varies depending on the structure (Börsch, 2007; Ernest, 2007; Prem, 2004). Nowicki and Góra (1993) studies on the 
structure of fragrant substances have shown that introducing changes in the spatial structure of the molecule can also affect the osmotic or aromatic properties of the compound. Thus, if we modify these odorant molecules (functional groups) either by replacing them with another or by changing their structural position, then it could tend to alter the smell or its interaction with the noise receptor. Previous studies have shown that stereochemical factors most affecting the flavour are the configuration of the double bond, and the configuration of chiral centres (Groussin and Antoniotti 2012; Harman, 2002; Woker, 1906). Accordingly, a simple rearrangement of the allyl function in an odorant can lead to drastic changes in odour quality. It is, therefore, possible to improve the olfactory quality of a fragrant material by chemical modification. Methyl eugenol is a naturally occurring substance found in the essential oils of several plant species. It is an abundant material but with limited interest as fragrance and flavouring ingredient.

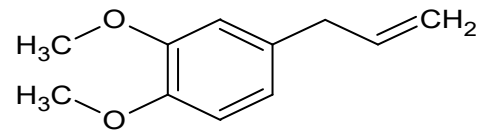

Fig 2: Structure of methyl eugenol (1, 2-dimethoxy-4-(prop-2-en1 -yl) benzene)

Some examples of common culinary herbs and spices that contain methyl eugenol are basil, tarragon, lemongrass, citronella, bay leaf, nutmeg, allspice, tea tree, cloves and mace. Methyl eugenol is also reported to have been found in oranges, bananas and grapefruit juice (Johnson and Abdo, 2005; Smith et al., 2002). Commercially prepared foods in which methyl eugenol may be found include ice cream; baked goods such as cookies, pies, pastries and buns; puddings and other gelatine-based desserts; condiments, soups and sauces, especially pesto; various meat products; candy and chewing gum; and beverages made with spices and herbs containing methyl eugenol (Council of Europe, 2001). Methyl eugenol could be modified by the chemical transformation of the double bond present to hydroxyether derivatives in a controlled manner. Chemical modification of methyl eugenol would be valuable if olfactory properties such as binding ability, volatility, and compatibility are concomitantly improved. Therefore, chemical modification of methyl eugenol molecular framework to introduce hydroxyether function(s), would be expected to generate more fragrant entity. A lot of work has been done on the metabolism of methyl eugenol (Xing et al., 2011; Gardner et al., 1997; Health Canada, 2007) but fewer in the area of fragrance enhancement. Also, despite the rich literature on the chemistry of epoxide and ring-opening, to the best of our knowledge, there are no reports concerning epoxide ring-opening of methyl eugenol epoxides by using alcohols. This paper will cover the epoxidation of methyl eugenol using 3Chloroperbenzoic acid (mCPBA) and ring opening of the epoxide formed with alcohol.

\section{MATERIALS AND METHODS}

Material: Methyl eugenol was purchased from Sigma Aldrich Company, USA. Solvents (n-hexane, acetone, ethyl acetate) were purchased from Fab Laboratory Nigeria Enterprise, Jos. 3-Chloroperbenzoic acid (mCPBA) was purchased from Acros Organics, USA. Other solvents and chemicals (Hydrogen peroxide, methanol, ethanol, dichloromethane, diethyl ether, hydrochloric acid, sodium hydroxide, sodium acetate, sodium bicarbonate, anhydrous sodium sulphate and sodium metal)were obtained from the Chemical Store, Nasarawa State University, Keffi. All chemicals were used as received. Silica gel and Thin-layer chromatography (TLC) plates were purchased from Fab Laboratory Nigeria Enterprise, Jos.

Instrumentation: The instrumentation used in this research was Nuclear Magnetic Resonance spectrometer (BRUKER TOPSPIN $300 \mathrm{MHz}$ ), located in Bioscience and Biotechnology Division, Los Alamos National Laboratory, Los Alamos, New Mexico, USA.

Experiment Procedure: Epoxidation of Methyl Eugenol: 3-Chloroperbenzoic acid (51.30 g, 297.27 $\mathrm{mmol})$, sodium bicarbonate $(8.0 \mathrm{~g}, 95.23 \mathrm{mmol})$ and $200 \mathrm{~cm}^{3}$ methylene chloride were placed in $500 \mathrm{~cm}^{3}$ round-bottom flask cooled by immersion in an icewater bath. The reaction was stirred with a magnetic stirrer. In another flask, methyl eugenol $(10.0 \mathrm{~g}, 56.08$ mmol) was dissolved in methylene chloride $\left(20 \mathrm{~cm}^{3}\right)$. The solution of methyl eugenol in DCM was added dropwise to a stirred mixture of mCPBA and $\mathrm{NaHCO}_{3}$. A pale yellow solution was formed. Following the addition of methyl eugenol, the reaction was stirred for additional $30 \mathrm{~min}$. The cooling bath was removed and the reaction was allowed to attain room temperature and stirred overnight. After $24 \mathrm{~h}$, the reaction was monitored by TLC [Silica gel; ethyl acetate: hexane, 3:7 v/v]. Thin-layer chromatography showed the reaction to be complete (no starting material spot in the reaction). To the reaction, methylene chloride (250 $\left.\mathrm{cm}^{3}\right)$ and $5 \% \mathrm{NaHCO}_{3}$ solution $\left(200 \mathrm{~cm}^{3}\right)$ was added. The mixture was transferred to a separatory funnel. The methylene chloride layer (lower) was removed. The aqueous phase was extracted with fresh methylene chloride $\left(100 \mathrm{~cm}^{3}\right)$. The combined organic phase was washed successively with brine $\left(200 \mathrm{~cm}^{3}\right)$, dried (anhydrous $\mathrm{Na}_{2} \mathrm{SO}_{4}$ ), and filtered. The solvent was removed under reduced pressure (Rotary evaporator) to give a crude product. The crude was purified by 
column chromatography. Fractions corresponding to the product were pooled and the solvent removed (Rotary evaporator) to afford the product [2-(4-ethyl- 3-methoxybenzyl) oxirane (methyl eugenol epoxide)] as a yellow, oily liquid [weight $=7.5 \mathrm{~g}$, percentage yield $=68.8]$. Product was analysed $\left({ }^{1} \mathrm{H}-\mathrm{NMR}\right)($ Fig 3$)$.<smiles>C=CCc1ccc(OC)c(OC)c1</smiles>

Scheme 1: Conversion of methyl eugenol to 2-(4-ethyl-3-methoxybenzyl) oxirane (Methyl eugenol epoxide)

Epoxide Ring Opening: Ethanol $\left(75 \mathrm{~cm}^{3}\right)$ was placed in $1 \mathrm{~L}$ beaker. The beaker was cooled with an ice-water bath. Concentrated sulphuric acid (6 drops) was added to the ice-cold ethanol. The mixture was allowed to stir for $5 \mathrm{~min}$. Separately, methyl eugenol epoxide $(2.8 \mathrm{~g}$, $214.42 \mathrm{mmol})$ was dissolved in ethanol $\left(25 \mathrm{~cm}^{3}\right)$ and added dropwise over $5 \mathrm{~min}$ to a stirred mixture of ethanol and $\mathrm{H}_{2} \mathrm{SO}_{4}$. The reaction mixture was stirred in the ice bath for an additional $20 \mathrm{~min}$. The ice bath was removed and the mixture was allowed to stir at room temperature overnight. After $24 \mathrm{~h}$, the reaction was monitored by TLC [Silica gel; ethyl acetate: hexane, $3: 7 \mathrm{v} / \mathrm{v}$ ]. To the reaction, methylene chloride $\left(250 \mathrm{~cm}^{3}\right)$ and $5 \% \mathrm{NaHCO}_{3}$ solution $\left(200 \mathrm{~cm}^{3}\right)$ was added. The mixture was transferred to a separatory<smiles>COc1ccc(CC2CO2)cc1OC</smiles>

2-(3,4-dimethoxybenzyl)oxirane

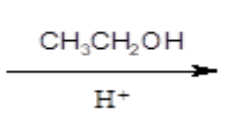

1-(3,4-dimethoxyphenyl)-3-ethoxypropan-2-ol funnel. The methylene chloride layer (lower) was removed. The aqueous phase was extracted with fresh methylene chloride $\left(100 \mathrm{~cm}^{3}\right)$. The combined organic phase was washed successively with brine $\left(200 \mathrm{~cm}^{3}\right)$, dried (anhydrous $\mathrm{Na}_{2} \mathrm{SO}_{4}$ ), and filtered. The solvent was removed under reduced pressure (Rotary evaporator) to give a crude product. The crude was purified by column chromatography. Fractions corresponding to the product were pooled and the solvent removed (Rotary evaporator) to afford the product [1-(3, 4-dimethoxyphenyl)-3-ethoxypropan2-ol] as a brick red, oily liquid [weight $=2.2 \mathrm{~g}$, percentage yield $=63.5]$. Product was analysed $\left({ }^{1} \mathrm{H}-\right.$ NMR) (Fig 5).

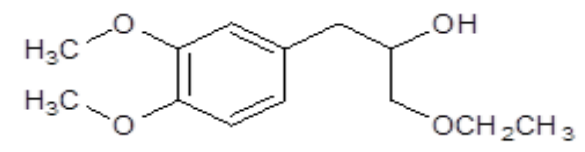

Scheme 2: Conversion of 2-(4-ethyl-3-methoxybenzyl) oxirane (Methyl eugenol epoxide) to 1-(3, 4-dimethoxyphenyl)-3-ethoxypropan-2-ol [DMPEP] (Ring opening)

\section{RESULTS AND DISCUSSION}

2-(3,4-dimethoxybenzyl)oxirane: The ( eugenol. It has $\mathrm{R}_{\mathrm{f}} 0.6$ by TLC [Silica gel; ethyl acetate: hexane, $3: 7 \mathrm{v} / \mathrm{v}$ ] which was lower than the $\mathrm{R}_{\mathrm{f}} 0.83$ by TLC [Silica gel; ethyl acetate: hexane, $3: 7 \mathrm{v} / \mathrm{v}$ ] of methyl eugenol (starting material) as a result of a polar group (oxygen) introduced. ${ }^{1} \mathrm{H}-\mathrm{NMR}$ was characterised (Fig 3).

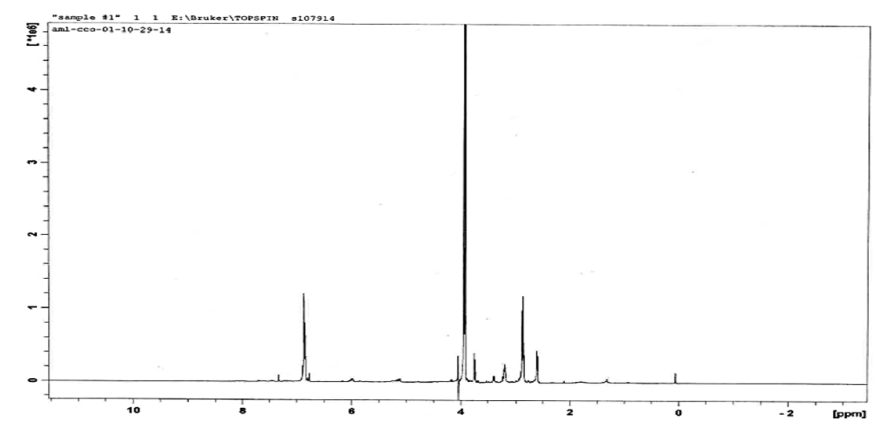

Fig 3: ${ }^{1} \mathrm{H}-\mathrm{NMR}$ spectrum of 2-(4-ethyl-3-methoxybenzyl) oxirane (Methyl eugenol epoxide)

Chemical shift and multiplicity are in agreement and fully matched spectra of the compound simulated using nmrdb.org (Fig 4) and chemdoodle.com simulator. Based on the questionnaire analysis, 2(3,4-dimethoxybenzyl)oxirane was characterized by floral $(40 \%)$, fresh $(20 \%)$, slight lime $(10 \%)$ and sweet $(30 \%)$ qualities. On the odour scale, $40 \%$ agree 2-(4-ethyl-3methoxybenzyl) oxirane has a medium-strong odour, while $60 \%$ agree with Strong Odour (Table 1).

Synthesis of DMPEP: 1-(3,4dimethoxyphenyl)-3-ethoxypropan2-ol [DMPEP] $(63.5 \%$ yield $)$ was synthesized from 2-(3,4dimethoxybenzyl)oxirane. 


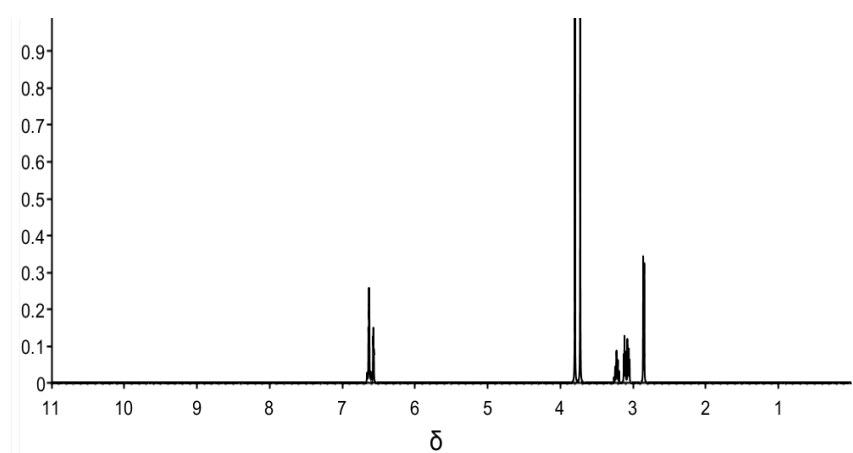

Fig 4: Simulated ${ }^{1} \mathrm{H}-\mathrm{NMR}$ spectrum of 2-(3,4-dimethoxybenzyl)oxirane (Methyl eugenol epoxide) from nmrdb.org

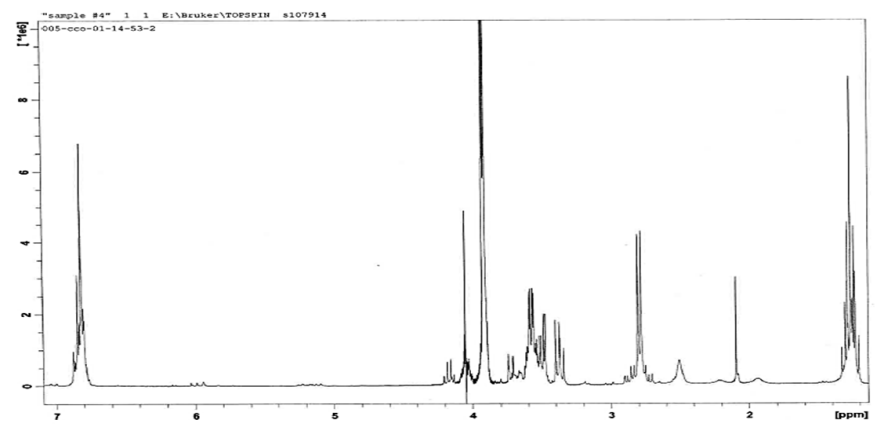

Fig. 5: ${ }^{1} \mathrm{H}-\mathrm{NMR}$ spectrum of 1-(3,4-dimethoxyphenyl)-3-ethoxypropan-2-ol (Ring-

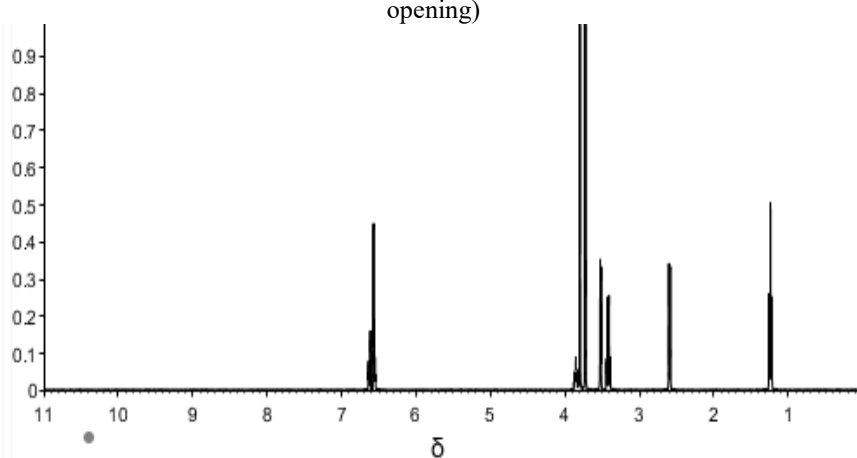

Fig 6: Simulated ${ }^{1} \mathrm{H}-\mathrm{NMR}$ spectrum of 1-(3, 4-dimethoxyphenyl)-3-ethoxypropan-2-ol (Ring-opening)from nmrdb.org

Table 1: Odour Test Results for 2-(3,4-dimethoxybenzyl)oxirane

\begin{tabular}{lrlr}
\hline \multicolumn{2}{c}{ Smell Test } & \multicolumn{2}{c}{ Odour concentration } \\
\hline Floral & $40 \%$ & Medium-strong odour & $40 \%$ \\
Fresh & $20 \%$ & Strong Odour & $60 \%$ \\
Slight lime & $10 \%$ & & \\
Sweet & $30 \%$ & & \\
\hline
\end{tabular}

Table 2: Odour Test Results for 1-(3, 4-dimethoxyphenyl)-3-ethoxypropan-2-ol

\begin{tabular}{|c|c|c|c|}
\hline Smell Test & & \multicolumn{2}{|c|}{ Odour concentration } \\
\hline Glue-like & $60 \%$ & $\begin{array}{l}\text { Medium- } \\
\text { strong } \\
\text { odour }\end{array}$ & $30 \%$ \\
\hline Pungent & $30 \%$ & $\begin{array}{l}\text { Strong } \\
\text { Odour }\end{array}$ & $70 \%$ \\
\hline Caramel-like & $10 \%$ & & \\
\hline
\end{tabular}

OKOPI, SO; AFFIKU, LM
The alcohol is more polar than the starting material (epoxide) because of the addition of an -OH group, hence, 1-(3,4-dimethoxyphenyl)-3ethoxypropan-2-ol has a lower $\mathrm{R}_{\mathrm{f}}$ (0.29) [Silica gel; ethyl acetate: hexane, $3: 7 \mathrm{v} / \mathrm{v}]$ compared to $\mathrm{R}_{\mathrm{f}}$ (0.6) [Silica gel; ethyl acetate: hexane, 3:7 $\mathrm{v} / \mathrm{v}]$ for starting epoxide. ${ }^{1} \mathrm{H}-\mathrm{NMR}$ was characterised (Figure 5). Chemical shift and multiplicity were in reasonable agreement with the spectra of the compound simulated using nmrdb.org (Figure 6) and chemdoodle.com simulator. The questionnaire analysis shows that 1(3,4-dimethoxyphenyl)-3-

ethoxypropan-2-ol was characterized by glue-like $(60 \%)$, pungent $(30 \%)$, and caramel-like $(10 \%)$ qualities. On the odour scale, $30 \%$ agree 1-(3,4dimethoxyphenyl)-3-ethoxypropan2-ol has a medium-strong odour, while $70 \%$ agree with a strong odour (Table 2).

Conclusion: The synthesised compounds have different odour which make them readily distinguishable from each other. The odour qualities change of the products depend significantly on the substitution. The epoxidation of methyl eugenol and ring opening of the oxirane with ethanol yielded (2(4-ethyl-3-methoxybenzyl) oxirane $(68.8 \%$ yield $)$ and (1- $(3,4-$ dimethoxyphenyl)-3-ethoxypropan2-ol $(63.58 \%$ yield $)$ respectively. The method effectively enhanced the olfactory properties of methyl eugenol.

\section{REFERENCE}

Antoniotti, S. (2014). Tuning of essential oil properties by enzymatic treatment: Towards sustainable processes for the generation of new fragrance ingredients. Molecules, 19(7): 9203-9214. 
Börsch, A. (2007). Small molecules make scents. The European J. Sci. Teachers 6:101

Brookes, J. C; Horsfield, A. P; Stoneham, A. M. (2009). Odour character differences for enantiomers correlate with molecular flexibility. Journal of the Royal Society, Interface, 6(30): 75-86.

Buck, L; Axel, R. (1991). A novel multigene family may encode odorant receptors: a molecular basis for odour recognition. Cell 65(1), 175-187.

Council of Europe, Committee of Experts on Flavouring Substances, (2001). UK note on estimated intakes of Methyl eugenol from foods and beverages. Document RD 4.9/1-48, submitted by the delegation of the UK for the 48th meeting in Strasbourg, April 2001. Strasbourg (FR): Council of Europe. 10 p.

Engen, T. (1982). The Perception of Odors. Academic Press, New York, U.S.A, p, 6.

Ernest, J. P. (2007). The Chemistry of Essential Oils and Artificial Perfumes. 4 Ed, Revised and Enlarged Published by Scott, Greenwood and Son 8 Broadway, Ludgate, London.

Gardner, I; Wakazono, H; Bergin, P; De waziers, I; Beaune, P; Kenna J.G; Cardwell, J. (1997). Cytochrome P450 Mediated Bioactivation of Methyl eugenol in Fischer 344 Rat and Human Liver Microsomes Carcinogenesis 18:1775-83

Groussin, A.-L; Antoniotti, S. (2012). Valuable chemicals by the enzymatic modification of molecules of natural origin: Terpenoids, steroids, phenolics and related compounds. Bioresource Technol., 115, 237-243.

Harman, S. J. (2002). Fragrance Applications: A Survival Guide. Carol Stream, IL: Allured Pub. Corp.

Health Canada (2007). The cosmetic ingredient hotlist - March 2007 [Internet]. Ottawa (ON): Health Canada, Consumer Product Safety. [cited 2009 Aug]. Available from: http://www.hcsc.gc.ca/cps-spc/person/cosmet/info-indprof/ hot-list-critique/hotlist-liste_e.html

Johnson, J. D; Abdo, K. M. (2005). Methyl eugenol in the diet: toxic and pathological aspects. In: Preedy, V. R., Watson, R. R. (ed). Reviews in food and nutrition toxicity, vol. 3. Boca Raton (FL): CRC Press, Taylor \& Francis Group, LLC.

Noma, Y; Asakawa, Y. (2010). Biotransformation of monoterpenoids. In Comprehensive Natural Products II: Chemistry and Biology. 3: 669-801

Nowicki, J; Góra, J. (1993). The chemical structure of a smell. Attempt analogy for example furfuryl compounds and benzyl. POLLENA-TŚPK 37, 134-139

Ohloff, G. (1992). Seventy-five years of scent and aroma chemistry, Helv Chim Acta 75:1341- 1415

Ohloff, G. (1994). Scent and fragrances: The fascination of odors and their chemical perspectives. Berlin: 127: Springer-Verlag.

Prem, L. (2004). Molecular Structure and Odor Mixture Perception. Unpublished Manuscript, Centre for Advanced Food Research, University of Western Sydney.

Sell, C. S. (2006). The Chemical of fragrances from perfumer to consumer. 2nd edition. The Royal Society of Chemicals. 44-53.

Serra, S; Fuganti, C; Brenna, E. (2005). Biocatalytic preparation of natural flavours and fragrances. Trends Biotechnol., 23, 193-198.

Smith, R. L; Adams, T. B; Doull, J; Feron, V. J; Goodman, J. I; Marnett, L. J; (2002). Safety assessment of allylalkoxybenzene derivatives used as flavouring substances-Methyl eugenol and estragole. Food Chem Toxicol 40:851-870.

Woker, G. (1902). The relations between structure and smell in organic compounds. J. Phys. Chem. 10:455.

Xing, Y; Xu, Q; Li, X; Che, Z; Yun, J. (2012), Antifungal activities of clove oil against rhizopus nigricans, aspergillus flavus and penicillium citrinum in vitro and in wounded fruit test. J. Food Safety, 32: 84-93.

Yao, W.-R.; Zhang, Y.-Z.; Chen, Y.; Yang, Z.-P. (2010). Aroma enhancement and characterization of the absolute osmanthus fragrans lour. J. Essent. Oil Res., 22, 97-102. 